\title{
蠕虫状孔道介孔 $\mathrm{SiO}_{2}$ 的合成及其固定化漆酶的活性
}

\author{
张剑波 ${ }^{a}$ 杨宇翔*, 田美娟 ${ }^{b}$ 邓常健 ${ }^{b}$ 曹䂞 ${ }^{b}$ 袁宏明 ${ }^{c}$ \\ ( ${ }^{a}$ 北京大学环境科学与工程学院 北京 100871) \\ ( ${ }^{b}$ 华东理工大学化学与分子工程学院 上海 200237) \\ ( ${ }^{c}$ 无机合成与制备化学国家重点实验室 吉林大学化学学院＼cjkstart长春 130012)
}

\begin{abstract}
摘要 以聚环氧乙烷-聚环氧丙烷-聚环氧乙烷三嵌段共聚物(P123)与离子型助表面活性剂 \{十六烷基三甲基溴化铵 (CTAB)、十二烷基硫酸钠(SDS)或 $N$-肉豆遥酰- $D$-丙氨酸 $\left.\left(\mathrm{C}_{14}-\mathrm{D}-\mathrm{A}\right)\right\}$ 为结构导向剂, 合成了蠕虫状孔道的介孔 $\mathrm{SiO}_{2}$, 并 在 P123/C $\mathrm{C}_{14}$ - D-A/TMAPS( $N$-三甲氧基硅丙基- $N, N, N$-三甲基氯化铵)合成反应体系中, 研究了扩孔剂聚乙二醇(PEG)- 400 的不同添加量对蠕虫状孔道的扩孔效果. 合成的产物分别用 X-射线衍射(XRD)、扫描电镜(SEM)、透射电镜(TEM)和 $\mathrm{N}_{2}$ 吸附进行表征. 此外, 利用溶剂萃取法对扩孔后的蠕虫状介孔 $\mathrm{SiO}_{2}$ 进行处理, 得到不同孔径的季铵盐官能团化介孔 $\mathrm{SiO}_{2}$, 分别用于漆酶的固定化; 并对固定化酶的稳定性、所需的最佳 $\mathrm{pH}$ 值以及降解 2,4-DCP 的重复利用性进行了研究. 通过比较研究发现, 介孔 $\mathrm{SiO}_{2}$ 孔径与漆酶分子直径的匹配性是影响固定化漆酶比活及降解 2,4-DCP 效率的重要因素. 关键词＼cjkstart蠕虫状介孔; 扩孔; 2,4-DCP; 降解效率; 重复利用性
\end{abstract}

\section{Synthesis of Worm-like Mesoporous Silica and Enzymatic Activity of the Immobilized Laccase}

\author{
Zhang, Jianbo $^{a} \quad$ Yang, Yuxiang*, $\quad$ Tian, Meijuan $^{b} \quad$ Deng, Changjian ${ }^{b}$ \\ Cao, Lei ${ }^{b} \quad$ Yuan, Hongming ${ }^{c}$ \\ ( ${ }^{a}$ Department of Environmental Sciences, Peking University, Beijing 100871, China) \\ $\left({ }^{b}\right.$ School of Chemistry and Molecular Engineering, East China University of Science \& Technology, \\ Shanghai 200237, China) \\ ( ${ }^{c}$ State Key Laboratory of Inorganic Synthesis and Preparative Chemistry, College of Chemistry, \\ Jilin University, Changchun 130012, China)
}

\begin{abstract}
Mesoporous silica with worm-like pore channels was synthesized using mixed P123 (polyethyleneoxide-polypropylene oxide-polyethylene oxide triblock copolymer $\mathrm{EO}_{20} \mathrm{PO}_{70} \mathrm{EO}_{20}$ ) and ionic cosurfactant \{CTAB, SDS or $\mathrm{N}$-myristoyl- $\mathrm{D}$-alanine $\left.\left(\mathrm{C}_{14}-\mathrm{D}-\mathrm{A}\right)\right\}$ as a structure-directing agent, and the pore-expanding effect of different amount of PEG-400 on the worm-like pore channels was studied. The synthesized products were characterized using X-ray diffraction, scanning electron microscopy, transmission electron microscopy, and nitrogen sorption analysis. Moreover, the worm-like pore-expanded mesoporous silica was extracted with solvent, and the obtained quaternary ammonium functionalized mesoporous silica with different pore size was applied to immobilize laccase respectively. The stability of immobilized laccase, the optimum $\mathrm{pH}$ value acquired and reusability for the degradation of 2,4-DCP were also studied. Through comparative studies, it is found that, matching of sizes between the enzyme molecule and the pore diameter of the mesoporous silica, is essential for specific activity of immobilized laccase and degradation efficiency of 2,4-DCP by immobilized laccase.
\end{abstract}

Keywords worm-like mesoporous silica; pore-expanding, 2,4-DCP; degradation efficiency; reusability

\section{1 引言}

随着现代农业的发展, 2,4-二氯酚农药(2,4-DCP)被 越来越多的用于农业生产过程中以减少病虫害的发生, 但却很难自然降解, 它可通过空气、水、土壤等潜入农 作物, 残留在粮食、蔬菜中, 经食物链在生物体中富集, 对人类的健康造成极大危害, 是环境优先控制污染物之 一. 用漆酶降解 2,4-DCP 是去除该类污染物的重要方法
之一. 漆酶是一种含铜多酚氧化酶，能够通过获得 $\mathrm{O}_{2}$ 催 化酚类物质，但自由酶容易在环境中失活. 通过将酶固 定的方法增强酶的稳定性以提高酶活力和使用寿命, 并 可重复使用.

介孔 $\mathrm{SiO}_{2}$ 作为一种无机材料, 具有孔道大小均一、 且在一定范围内连续可调的孔径, 比表面积大且具有较 高的水热稳定性等特点, 是固定漆酶的良好载体. 相比 于二维六方结构的介孔二氧化硅，蠕虫状孔道的介孔

\footnotetext{
*E-mail: yxyang@ecust.edu.cn
}

Received November 8, 2012; published February 1, 2013.

Supporting information for this article is available free of charge via the Internet at http://sioc-journal.cn. 
$\mathrm{SiO}_{2}$ 具有较大的孔径、较厚的孔壁和相互连通的三维孔 道, 有利于较大尺寸客体酶分子在其孔道内扩散 ${ }^{[1 \sim 3]}$, 在催化、酶固定化等领域中均显出独特优势, 从而引起 越来越多的关注.

P123 作为一种非离子的两亲性嵌段聚合物, 可以 直接合成孔径 $6.5 \sim 7.5 \mathrm{~nm}$, 孔壁厚为 $4.5 \sim 5.3 \mathrm{~nm}$ 的大 孔六方孔道结构的介孔 $\mathrm{SiO}_{2}{ }^{[4]}$. 而 P123 由亲水性 $\mathrm{EO}$ 链 段和疏水性 PO 链段组成, 由于其分子链容易受外界因 素的影响, 譬如酸的浓度、加入助表面活性剂 ${ }^{[5]}$ 等. 因此 通过选择不同的 $\mathrm{pH}$ 值, 可以调控材料的介观相. 例如 随着 $\mathrm{pH}$ 升高, 六方孔道结构会转化为蠕虫状孔道的介 孔 $\mathrm{SiO}_{2}{ }^{[6]}$, 进行表面烷基化改性后, 接枝的烷基数目远 超过六角孔道结构的介孔 $\mathrm{SiO}_{2}$.

目前, 国外用非离子型两亲性嵌段聚合物加入离子 型助表面活性剂, 制备分级孔系统的蠕虫状孔道介孔 $\mathrm{SiO}_{2}$ 的研究引起了人们广泛的兴趣 ${ }^{[7,8]}$. 本文以 $\mathrm{P} 123$ 和 离子型助表面活性剂为结构导向剂, 讨论了合成条件对 产物有序度的影响; 并首次讨论了扩孔剂 PEG 对蠕虫 状孔道的影响规律以及加入不同类型的助表面活性剂 对产物结构的影响. 在此基础上, 本文在介孔 $\mathrm{SiO}_{2}$ 的合 成体系中加入含有季铵盐官能团的 TMAPS 为助结构导 向剂(Co-Structure Directing Agent, 简称 CSDA), 用溶 剂萃取法除去模板剂, 并首次利用季铵盐官能团化的介 孔 $\mathrm{SiO}_{2}$ 固定化酶, 进行降解 2,4-DCP 的研究, 讨论了载 体的孔径, 孔体积等参数对固定化酶降解 2,4-DCP 活性 的影响.

\section{2 实验结果及讨论}

\section{1 合成条件对产物结构的影响}

如图 1a 所示, 合成产物经传烧后在 $2 \theta=1.08^{\circ}$ 处存 在一个强衍射峰, 但是该衍射峰的半峰宽较大, 说明该 条件下合成的产物有序度较差. 图 $1 \mathrm{~b}$ 中, 当在合成体系 中加入乙醇后, 合成产物在炦烧前后的强衍射峰分别出 现在 $2 \theta=0.93^{\circ}$ 和 $2 \theta=1.01^{\circ}$ 处, 且煅烧后的半峰宽明显 变小, 说明合成产物在炦烧前后均保持有序的介孔结构 而且煅烧后产物的有序度较高. 如图 1c 所示, 当在合成 体系中加入 TMAPS 后, 虽然合成产物在炦烧前没有明 显的衍射峰, 但经炦烧后在 $2 \theta=0.90^{\circ}$ 处存在一个强衍 生峰, 该峰半峰宽小, 与图 $1 \mathrm{~b}$ 相比, 此峰相对较高, 说 明在体系中再加入 TMAPS 后, 合成产物具有较高的有 序度.

\section{2 在 P123 体系中加入不同类型表面活性剂对产物 结构的影响}

\subsubsection{XRD 分析}

图 2 为 P123 与不同类型表面活性剂混合后制得样 品炦烧前后的 XRD 图. 从图中可以看到, 虽然由 P123/CTAB 体系制得的产物在炦烧前没有明显的衍射

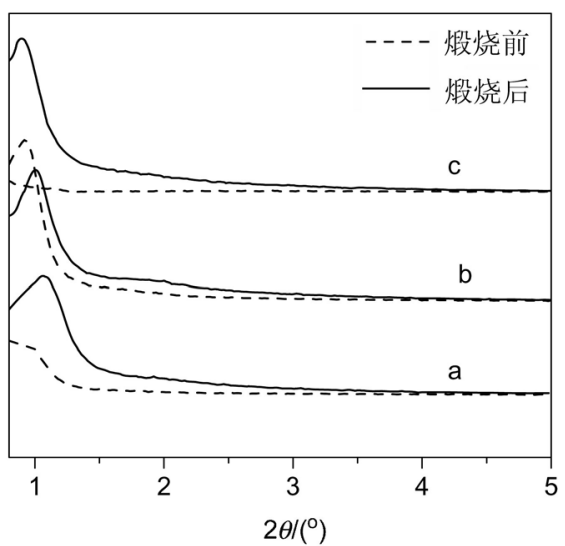

图 1 不同合成条件下制得样品烊烧前后的 XRD 图

Figure 1 XRD patterns of samples synthesized by different synthesis conditions

(a) a typical P123/C $14-\mathrm{D}-\mathrm{A}$ system; (b) $\mathrm{P} 123 / \mathrm{C}_{14}-\mathrm{D}-\mathrm{A} / \mathrm{EtOH}$ system; (c) P123/C $14-\mathrm{D}-\mathrm{A} / \mathrm{TMAPS}$ system

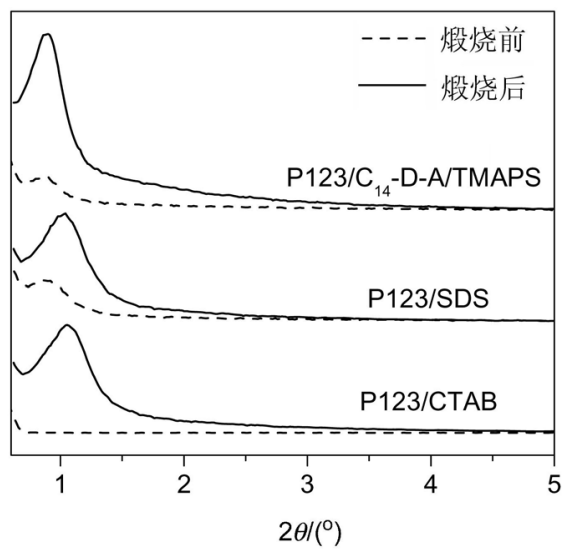

图 2 不同表面活性剂与 P123 混合制得样品煅烧前后的 XRD 图 Figure 2 XRD patterns of samples synthesized by different surfactants mixed with P123

峰, 但是㶹烧后的产物在 $2 \theta=1.06^{\circ}$ 处存在一个强衍射 峰. 而由 P123/SDS 体系和 P123/C $14-\mathrm{D}-\mathrm{A} / \mathrm{TMAPS}$ 体系制 得的产物在炦烧前有弱衍射峰, 经过煅烧后, 产物分别 在 $2 \theta=1.02^{\circ}$ 和 $2 \theta=0.90^{\circ}$ 处各存在强衍射峰. 说明合成 产物经过炦烧后有序度明显提高. 且三个样品经炦烧后 只有一个强衍射峰而没有其它衍射峰存在, 说明产物可 能具有蠕虫状的孔道结构. 且从 XRD 的峰形看出由 P123/C $14-\mathrm{D}-\mathrm{A} / \mathrm{TMAPS}$ 体系制得的产物煅烧后有序度最高.

\subsection{2 $\mathrm{N}_{2}$ 吸附一脱附测试分析}

图 3 为不同表面活性剂与 P123 混合制得样品炦烧 后的氮吸附等温线. 三个样品的吸附一脱附等温线均呈 现 IUPAC 分类中的 IV 型吸附等温线的特征, 是典型的 介孔材料吸附曲线. 另外, 三个样品在中压段到接近饱 和蒸气压段时均存在一个滞后环，滞后环的类型归属于 $\mathrm{H}_{2}$ 型, 表明其介孔结构均由瓶形孔 ${ }^{[9]}$ 组成. 由 P123/CTAB 体系、P123/C $14-\mathrm{D}-\mathrm{A} / \mathrm{TMAPS}$ 体系和 $\mathrm{P} 123 / \mathrm{SDS}$ 体系制得产物的吸附突跃依次发生在 $p / p_{0}=$ $0.3 \sim 0.6,0.4 \sim 0.7$ 和 $0.4 \sim 0.6$ 区域. 


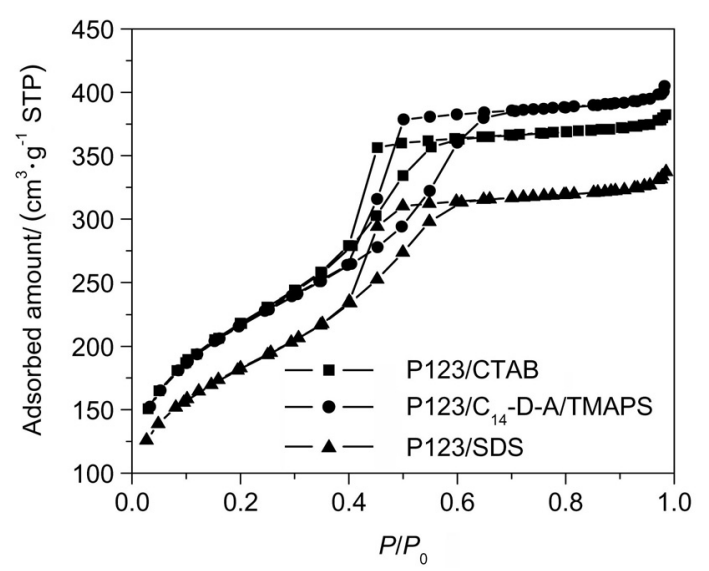

图 3 不同表面活性剂与 P123 混合制得样品煅烧后的氮吸附等温线 Figure 3 Nitrogen sorption/desorption isotherms of the calcined samples synthesized by different surfactants mixed with P123

图 4 为不同表面活性剂与 P123 混合制得样品煅烧 后的脱附孔径分布图. 总体来说, 三个样品的孔径分布 范围都很小, 说明产物孔径均匀. 其中, 以 P123/CTAB 体系制得样品的平均孔径最小, 且孔径分布范围最窄. 这是由于 P123 与硅源通过氢键、范德华作用力等组装, CTAB 与硅源的结合通过静电作用组装, 所以在 P123 体系中加入 $\mathrm{CTAB}$ 后, P123 和 CTAB 的混合胶束与硅源 的结合力增强, 提高胶束排列的有序度, 因而得到平均 孔径较小、孔径分布窄的介孔 $\mathrm{SiO}_{2}$ (见表 1).

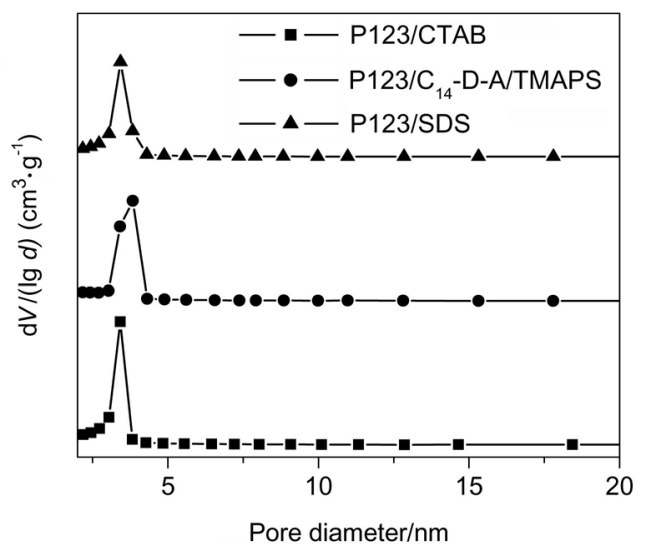

图 4 不同表面活性剂与 P123 混合制得样品㷽烧后的孔径分布图

Figure 4 Pore size distribution of the calcined samples formed by different surfactants mixed with P123

SDS 阴离子与 P123 分子中的 PPO 段相互作用形成 复合物分散在水溶液中, 由于 P123 和 SDS 间的相互作 用使 P123 中疏水的 PPO 段和 SDS 的长链紧密的结合在 一起, 抑制了 P123 胶束的形成 ${ }^{[10]}$, 所以溶液中大分子 复合物胶束由于 $\operatorname{SDS}$ 的加入而下降, 溶液中出现了由 部分混合胶束破裂形成的分子链, 使样品具有较小的比 表面和孔体积(见表 1).

$N$-肉豆冦酰- $D$-丙氨酸 $\left(\mathrm{C}_{14}-\mathrm{D}-\mathrm{A}\right)$ 是双极性头的阴离 子表面活性剂, 当 P123 和 $\mathrm{C}_{14}-\mathrm{D}-\mathrm{A}$ 相互作用时, P123 中
表 1 不同表面活性剂与 P123 混合制得样品便烧后的孔结构参数

Table 1 Porous properties of samples formed by different surfactants mixed with P123

\begin{tabular}{llcccc}
\hline P123/surfactant & \multicolumn{3}{l}{$d_{001}{ }^{a} S_{\mathrm{BET}}{ }^{b} /\left(\mathrm{m}^{2} \cdot \mathrm{g}^{-1}\right)$} & $V_{\mathrm{P}}{ }^{c} /\left(\mathrm{cm}^{3} \cdot \mathrm{g}^{-1}\right)$ & $D^{d} / \mathrm{nm} L^{e} / \mathrm{nm}$ \\
\hline $\mathrm{P} 123 / \mathrm{CTAB}$ & 8.33 & 780.6 & 0.591 & 3.03 & 5.30 \\
$\mathrm{P} 123 / \mathrm{SDS}$ & 8.65 & 655.6 & 0.522 & 3.18 & 5.47 \\
$\mathrm{P} 123 / \mathrm{C}_{14}-\mathrm{D}-\mathrm{A} / \mathrm{TMAPS}$ & 9.81 & 779.1 & 0.626 & 3.22 & 6.59 \\
\hline
\end{tabular}

${ }^{a}$ The interplanar spacing of 001 surface; ${ }^{b}$ specific surface area, calculated according to the BET method; ${ }^{c}$ pore volume; ${ }^{d}$ average pore size, according to the BJH method from $\mathrm{N}_{2}$ adsorption-desorption desorption branch calculation; ${ }^{e}$ pore wall thickness.

疏水的 PPO 段和 $\mathrm{C}_{14}-\mathrm{D}-\mathrm{A}$ 的长链紧密结合在一起, 但 $\mathrm{C}_{14}$-D-A 分子的氨基由于酸性条件形成氨基阳离子使每 股 $\mathrm{C}_{14}$-D-A 胶束之间产生静电排斥作用, 因而对紧密结 合在一起的 P123 胶束未能起到抑制作用, 故样品具有 较大的平均孔径、比表面和孔体积(见表 1). 此外, 由于

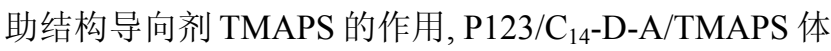
系制备的介孔 $\mathrm{SiO}_{2}$ 具有较高的晶面间距, $d_{001}$ 值达到最 高为 9.81. 说明 TMAPS 参与了介孔 $\mathrm{SiO}_{2}$ 结构的自组装 过程.

\subsubsection{TEM 分析}

图 $5 \mathrm{a}, 5 \mathrm{~b}$ 和 $5 \mathrm{c}$ 为不同表面活性剂与 $\mathrm{P} 123$ 混合制得 样品㷽烧后的 TEM 图. 图 5a, 5b 和 $5 \mathrm{c}$ 三个样品均具有 蠕虫状的孔道结构. 可能是由于三种不同类型的离子型 表面活性剂分别通过插入的方式与 P123 形成混合胶束, 并均与 P123 发生相互作用, 使 P123 中疏水的 PPO 段与 三种离子型表面活性剂的长链紧密的结合在一起, 导致 混合超分子聚集体的形成，而这种作用是形成图 6 分级 孔蠕虫状孔道介孔 $\mathrm{SiO}_{2}$ 的主要原因 ${ }^{[11]}$. 由于不同类型 的离子型表面活性剂本身性质的差异, 导致与 P123 在 形成混合胶束过程中的影响也不同. 粗略测定, 三个样 品的孔径分别为 $3.60,4.0$ 和 $4.4 \mathrm{~nm}$. P123/ $\mathrm{C}_{14}-\mathrm{D}-\mathrm{A} /$ TMAPS 体系制备的介孔 $\mathrm{SiO}_{2}$ 孔径最大, 与 $\mathrm{N}_{2}$ 吸附-脱 附测试分析的结果一致.

研究表明, 以非离子型表面活性剂为导向剂的合成 符合 $\mathrm{N}^{0} \mathrm{I}^{0}$ 的合成路径 ${ }^{[12]}$, 其中, $\mathrm{N}^{0}$ 是非离子表面活性剂, $\mathrm{I}^{0}$ 是 TEOS 的水化 $\mathrm{SiO}_{2}$ 低聚物. 然而体系中加入不同类 型的表面活性剂对合成路径产生一定的影响. 对于 P123 的混合体系而言, 当在体系中加入阳离子表面活 性剂 CTAB 时, 反应的合成路径变成 $\mathrm{N}^{0}\left(\mathrm{X}^{-} \mathrm{S}^{+}\right) \mathrm{I}^{+[11]}$, 其 中, $\mathrm{X}^{-}$为 $\mathrm{NO}_{3}{ }^{-}, \mathrm{S}^{+}$为阳离子表面活性剂, $\mathrm{I}^{+}$是 TEOS 的水 化 $\mathrm{SiO}_{2}$ 低聚物; 在体系中加入阴离子表面活性剂 SDS 时, 反应的合成路径变成 $\mathrm{N}^{0}\left(\mathrm{~S}^{-}\right) \mathrm{I}^{+}$, 其中, $\mathrm{S}^{-}$为阴离子表 面活性剂, $\mathrm{I}^{+}$仍是水化 $\mathrm{SiO}_{2}$ 低聚物.

对于 P123/C $14-\mathrm{D}-\mathrm{A} / \mathrm{TMAPS}$ 的混合体系而言, $N$-肉 豆莞酰- $D$-丙氨酸 $\left(\mathrm{C}_{14}-\mathrm{D}-\mathrm{A}\right)$ 是双极性头的阴离子表面活 性剂, TMAPS 带正电荷, 作为助结构导向剂具有能与有 机硅源如 TEOS 共缩聚的基团. 在体系中加入氨基酸类 阴离子表面活性剂 $\mathrm{C}_{14}$-D-A 和 TMAPS, 反应的合成路 

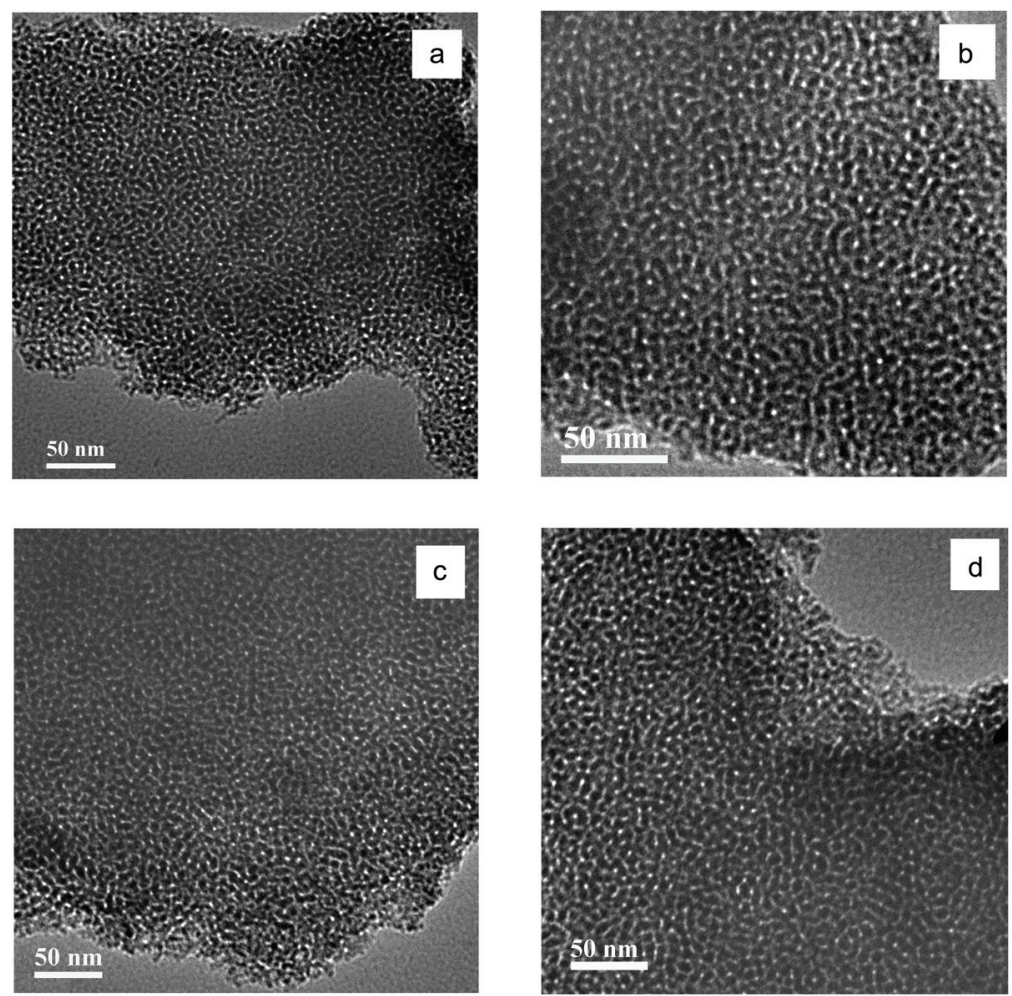

图 5 不同表面活性剂与 P123 混合制得样品煅烧后的 TEM 图

Figure 5 TEM patterns of calcined samples synthesized by different surfactants mixed with P123

(a) P123/CTAB, (b) P123/SDS, (c) P123/C14-DA/TMAPS (calcination method), (d) P123/C14-DA/TMAPS (extraction method)

径转变成 $\mathrm{N}^{0}\left(\mathrm{~S}^{-} \mathrm{N}^{++}\right) \mathrm{I}^{+}$, 其中, $\mathrm{S}^{-}$为氨基酸类阴离子表面 活性剂, $\mathrm{N}^{+}$为 TMAPS 的氨基阳离子基团, $\mathrm{I}^{+}$是水合硅 酸的低聚物 ${ }^{[11]}$.

由上可知, CTAB、SDS 和 $\mathrm{C}_{14}-\mathrm{D}-\mathrm{A}$ 与 P123 形成混 合胶束后，对 P123 嵌段共聚物的胶束形成具有明显的 作用, 离子型表面活性剂与 P123 中疏水的 PPO 段的作 用降低混合胶束的自组装作用, 因而导致反应的合成路 径发生了变化.

\section{3 扩孔剂 PEG 添加量对产物结构的影响}

\subsubsection{XRD 分析}

图 6 为在 P123/C $14-\mathrm{D}-\mathrm{A} / \mathrm{TMAPS}$ 体系中加入不同体 积扩孔剂 PEG 后制得样品煅烧后的 XRD 图. 所得产物 均存在明显的强衍射峰, 说明 PEG 的加入不会影响有 序介孔结构的形成. 但是, 加入不同体积 PEG 制得样品 经烊烧后在峰高、半峰宽等指标方面存在明显差异, 说 明 PEG 的加入量对产物的有序度存在一定的影响. 总 的来看, 随着体系中 PEG 比例的增加, 主峰的出峰位置 依次向左发生横移, 所得产物依次在 $2 \theta=0.99^{\circ}, 0.87^{\circ}$, $0.86^{\circ}, 0.84^{\circ}$ 和 $0.83^{\circ}$ 处存在强衍生峰, $2 \theta$ 值逐渐减小, 其 相对应的晶面间距 $d$ 值依次为 $8.916,10.146,10.264$, 10.508 和 $10.635 \mathrm{~nm}$, 说明扩孔剂 PEG 使有序介孔结构 的晶面间距发生了变化, 从而使介孔 $\mathrm{SiO}_{2}$ 的孔结构发 生变化. 随着扩孔剂 PEG 加入量的增加, 晶面间距也随 着增加. 其中, 当 $\mathrm{P} 123 / \mathrm{PEG}$ 的摩尔比是 $1: 15$ 时, 煅烧
产物的主峰最高, 且半峰宽较小, 说明该条件下合成的 产物有序度最好. 此时, 相对应的晶面间距 $d$ 值也较大, 为 $10.508 \mathrm{~nm}$, 从理论上讲, 应当有较好的扩孔效果.

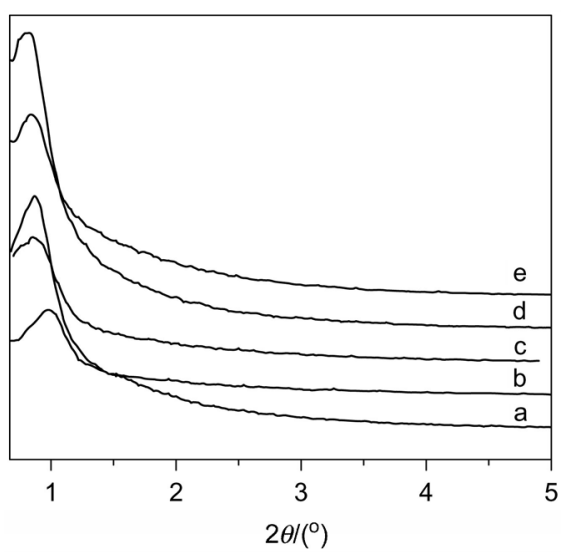

图 6 添加不同体积 PEG 制得样品㷽烧后的 XRD 图(P123/C $14-\mathrm{D}-$ A/TMAPS 体系)

Figure 6 XRD patterns of calcined samples synthesized by different PEG volumes

(a) $\mathrm{P} 123 / \mathrm{PEG}=1: 1$; (b) $\mathrm{P} 123 / \mathrm{PEG}=1: 5$; (c) $\mathrm{P} 123 / \mathrm{PEG}=1: 10$; (d) $\mathrm{P} 123 / \mathrm{PEG}=1: 15 ;$ (e) $\mathrm{P} 123 / \mathrm{PEG}=1: 20$

\subsubsection{SEM 分析}

图 7 为在 P123/C $14-\mathrm{D}-\mathrm{A} / \mathrm{TMAPS}$ 体系中加入不同体 积扩孔剂 PEG 后制得样品煅烧后的 SEM 图. 从图中可 以发现，随着体系中 PEG 比列的增加，产物的表面弯曲 
逐渐增大, 形貌由不规则近球形逐渐变为球形结构.

主要是因为介孔结构的形成, 实质上包括表面活性 剂 $/ \mathrm{SiO}_{2}$ 复合聚集体自组装成为具有液晶相的交联嵌段 共聚物 $/ \mathrm{SiO}_{2}$ 物种; $\mathrm{SiO}_{2}$ 物种的缩合, 使该液晶相随时间 进一步凝聚最终从水相中分离出来. 相分离后的液晶相 进一步生长为介孔相, 因此相分离的趋势决定了产物的 最终形貌 ${ }^{[13]}$. 如果相分离发生的早, 颗粒形貌的形成与 有序介孔结构的形成同时发生. 但是如果慢了, 为了降 低液晶相的表面能, 产物会形成弯曲度更大的形貌. 图 7 中的结果, 正是由于体系中 PEG 比例增加延长了分离 时间，使所得产物的表面弯度增加.
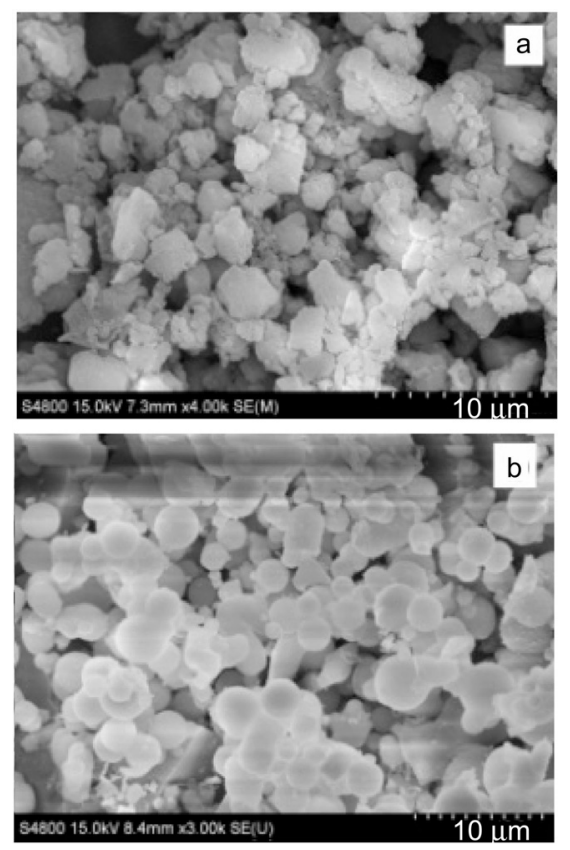

图 7 添加不同体积 PEG 制得样品煅烧后的 SEM 图(P123/C $14-\mathrm{D}-\mathrm{A} /$ TMAPS 体系)

Figure 7 SEM patterns of calcined samples synthesized by different PEG volumes

(a) $\mathrm{P} 123 / \mathrm{PEG}=1: 5$, (b) $\mathrm{P} 123 / \mathrm{PEG}=1: 15$

\subsection{3 $\mathrm{N}_{2}$ 吸附一脱附测试分析}

图 8 为添加不同体积 PEG 的氮吸附等温线及孔径 分布图. 样品的吸附等温线均呈现 IUPAC 分类中的 IV 型吸附等温线的特征, 是典型的介孔材料吸附曲线. 它 们在中压段和接近饱和蒸气压时均有明显的滞后环, 它 们滞后环的类型归属于 $\mathrm{H}_{2}$ 型, 表明其介孔结构均由瓶 形孔 ${ }^{[9]}$ 组成, 说明样品经过扩孔后, 介孔结构均未发生 改变, 只是孔结构参数发生了变化. 五个样品的吸附突 跃分别发生在 $p / p_{0}=0.40, p / p_{0}=0.39, p / p_{0}=0.38, p / p_{0}=$ 0.39 和 $p / p_{0}=0.39$.

表 2 中 PEG 的加入量对产物的孔结构参数具有显 著的影响. 将 5 个样品的孔结构参数与未加 PEG 比较分 析后, 加入 PEG 产物的孔结构呈现周期性变化, 当 P123/PEG 的摩尔比是 $1 / 10$ 或 $1 / 15$ 时, 合成样品的孔径
为 $3.64,3.68$, 扩孔效果最佳, 但 $S_{\mathrm{BET}}$ 和 $V_{\mathrm{P}}$ 与未加 $\mathrm{PEG}$ 的参数比较接近. 而当 P123/PEG 低于 $1 / 10$ 或高于 $1 / 15$ 时, 扩孔效果较差. 当 $\mathrm{P} 123 / \mathrm{PEG}=1 / 5$ 和 $1 / 20$ 时, 合成 样品的孔径与未加 PEG 的基本相同, 但 $S_{\mathrm{BET}}$ 和 $V_{\mathrm{P}}$ 均远 高于未加 PEG 样品的参数. 这可能是 PEG 的加入使样 品孔壁含孔多于未加 PEG 样品, 因而造成孔径不变, 而 表面积和孔体积皆增加.

表 2 添加不同体积 PEG 合成样品的孔结构参数

Table 2 Porous properties of samples with different PEG volumes

\begin{tabular}{lcccc}
\hline $\begin{array}{c}\text { P123/PEG } \\
\text { (moral ratio) }\end{array}$ & $S_{\mathrm{BET}}{ }^{a} /\left(\mathrm{m}^{2} \cdot \mathrm{g}^{-1}\right)$ & $V_{\mathrm{P}}^{b} /\left(\mathrm{cm}^{3} \cdot \mathrm{g}^{-1}\right)$ & $D^{c} / \mathrm{nm}$ & 酶比活 $/\left(\mathrm{U} \cdot \mathrm{g}^{-1}\right)$ \\
\hline 未加 $\mathrm{PEG}^{d}$ & 779.1 & 0.626 & 3.22 & 165.0 \\
$1: 1$ & 841.9 & 0.749 & 3.56 & 247.5 \\
$1: 5$ & 918.4 & 0.736 & 3.20 & 253.2 \\
$1: 10$ & 768.0 & 0.601 & 3.64 & 375.7 \\
$1: 15$ & 806.8 & 0.633 & 3.68 & 410.0 \\
$1: 20$ & 914.3 & 0.742 & 3.25 & 216.2 \\
\hline
\end{tabular}

${ }^{a}$ Specific surface area, calculated according to the BET method; ${ }^{b}$ pore volume; ${ }^{c}$ mean pore size, according to the BJH method by $\mathrm{N}_{2}$ adsorption-desorption, adsorption branch calculation obtained; ${ }^{d}$ data from Table 1.

\section{4 萃取法制备介孔二氧化硅载体}

\subsubsection{XRD 分析}

图 9 中萃取后的样品均存在强衍射峰, 说明所有的 样品在萃取后仍保持良好的介孔结构, 萃取过程对于产 物的结构没有明显影响. 随着 PEG 体积的增加, 萃取后 样品的衍射峰依次出现在 $2 \theta=0.74^{\circ}, 0.76^{\circ}, 0.86^{\circ}, 0.76^{\circ}$, $0.83^{\circ}$ 和 $0.74^{\circ}$ 处. 其中, 当 $\mathrm{P} 123 / \mathrm{PEG}=1: 15$ 时, 炦烧产 物的主峰最高且半峰宽较小, 说明该条件下合成的产物 有序度最好.

\section{4 .2 红外光谱及元素分析}

图 10 为萃取后样品的红外光谱图. 如图 10 所示, 在 $3440.0 \mathrm{~cm}^{-1}$ 处宽的吸收带，是由 $\mathrm{OH}$ 基团的伸缩振动 引起的. 2429.2 和 $1479.1 \mathrm{~cm}^{-1}$ 处的吸收峰属于季铵基团 上的甲基的变角振动峰. $1635.7 \mathrm{~cm}^{-1}$ 处的吸收峰是由 $\mathrm{H}-\mathrm{O}-\mathrm{H}$ 的弯曲振动引起的. $\mathrm{Si}-\mathrm{O}-\mathrm{Si}$ 反对称伸缩振 动引起的强吸收带出现在 $1089.0 \mathrm{~cm}^{-1}$. $\mathrm{Si}-\mathrm{O}$ 的弯曲振 动引起的吸收峰分别出现在 $962.0,802.4,465.3 \mathrm{~cm}^{-1}$. 此外, 图 10 中不存在其它的红外谱峰, 说明萃取后的产 物为含有季铵盐的纯介孔 $\mathrm{SiO}_{2}$ 载体, 表面活性剂已经 被除去. 根据元素分析可知，载体的含氮量为 $0.87 \%$.

2.4.3 不同扩孔剂 PEG 添加量对固定酶比活和降解 2,4-DCP 农药的影响

从表 2 可知, 当 $\mathrm{P} 123 / \mathrm{PEG}$ 物质的量比例为 $1: 15$ 时, 固定酶的比活最高, 达到 $410.0 \mathrm{U} / \mathrm{g}$; 物质的量比例 为 $1: 10$ 时, 酶比活其次; 未加 PEG 时, 固定酶的比活 最低, 为 $165.0 \mathrm{U} / \mathrm{g}$. 这是由于 $\mathrm{P} 123 / \mathrm{PEG}$ 物质的量比例 为 $1: 15$ 时, 孔径最大, 该载体的孔径和孔体积可以跟 漆酶实现很好的匹配, 进入到孔道内的底物愈创木酚分 

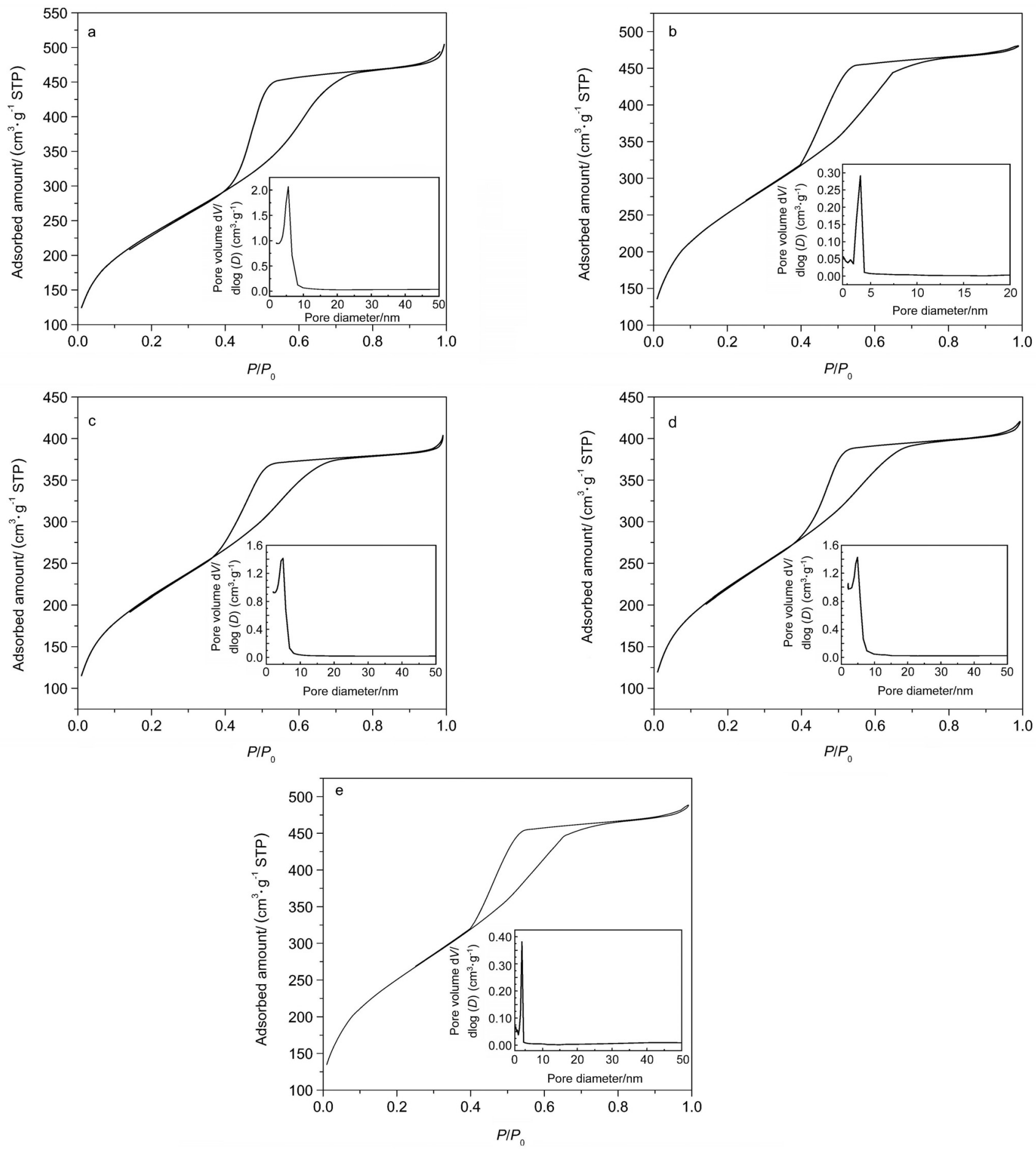

图 8 添加不同体积 PEG 制得样品㷽烧后的氮吸附等温线及孔径分布图

Figure 8 Nitrogen sorption/desorption isotherms and pore size distribution of the calcined samples synthesized by different PEG volumes (a) $\mathrm{P} 123 / \mathrm{PEG}=1: 1$; (b) $\mathrm{P} 123 / \mathrm{PEG}=1: 5$; (c) $\mathrm{P} 123 / \mathrm{PEG}=1: 10$; (d) $\mathrm{P} 123 / \mathrm{PEG}=1: 15$; (e) $\mathrm{P} 123 / \mathrm{PEG}=1: 20$

子的活性位点很容易与漆酶的活性位点结合, 从而能够 使固定酶的活性得到较好的表达，固定酶的比活最高.

由图 $5 \mathrm{~d}$ 可知, 萃取后的载体介孔 $\mathrm{SiO}_{2}$ 仍然具有蠕 虫状的孔道, 粗略测定, 孔径大约在 $4.6 \mathrm{~nm}$, 略高于煅 烧后的载体 $\mathrm{SiO}_{2}$. 而漆酶的分子直径大约在 $4 \mathrm{~nm}$, 长度 约 $15 \mathrm{~nm}$, 分子量为 $66000 \mathrm{Da}^{[14,15]}$, 比较漆酶的分子直 径和蠕虫状孔孔径大小，可以判断两者相匹配. 根据
Zimmerman ${ }^{[15]}$, 漆酶分子能够固定于孔直径为 $4 \mathrm{~nm}$ 的 介孔 $\mathrm{SiO}_{2}$ 开口上，这说明漆酶分子能够完全固定于本 文的蠕虫状孔内表面. 研究表明 ${ }^{[16]}$, 蠕虫状孔道是一种 三维孔道，与一般的二维孔道相比，三维孔道具有连通 的孔道，这不仅有利于酶的固定，而且可以防止酶分子 的泄漏，同时，弥补了载体在孔径方面的不足. 


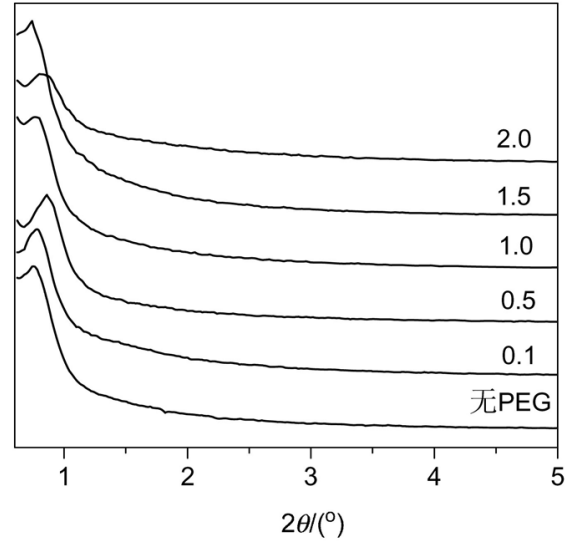

图 9 不同 PEG 量制备介孔二氧化硅萃取后的 XRD 图

Figure 9 XRD patterns of extraction samples synthesized by different PEG volumes

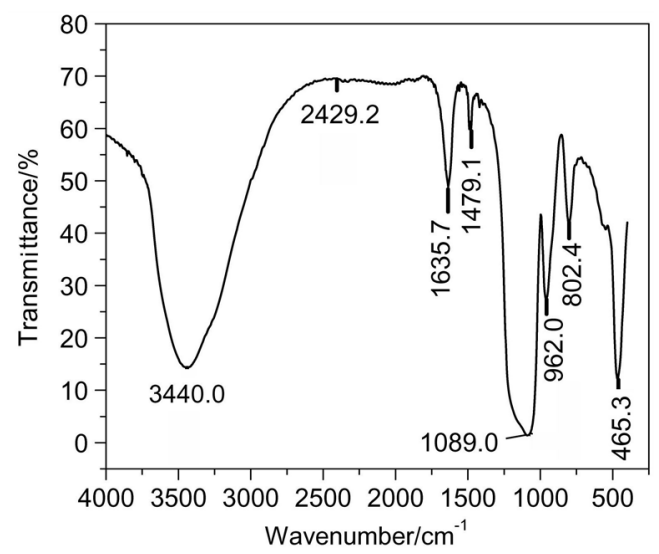

图 10 添加 $1.0 \mathrm{~mL}$ PEG 萃取后的红外光谱图

Figure 10 IR pattern of calcined sample synthesized by $1.0 \mathrm{~mL}$ PEG

当 P123/PEG 物质的量比例为 $1: 10$ 时, 载体介孔 $\mathrm{SiO}_{2}$ 的孔径稍低于物质的量比例为 $1: 15$ 的孔径, 因而 与漆酶分子的匹配性相对较低, 使得固定酶的比活降低, 如表 2 所示. 未加 PEG 时, 载体介孔 $\mathrm{SiO}_{2}$ 的孔径较低, 与漆酶分子的匹配性较差, 使得固定酶的比活大幅度降 低.

将去除率, 吸附率及降解率对扩孔剂 PEG 添加比 例 $(R)$ 作图, 得图 11. 而以下讨论中 $\mathrm{R}_{1}, \mathrm{R}_{5}, \mathrm{R}_{10}, \mathrm{R}_{15}$ 和 $\mathrm{R}_{20}$ 分别指 $\mathrm{P} 123 / \mathrm{PEG}$ 物质的量比例为 $1: 1,1: 5,1: 10$, $1: 15$ 和 $1: 20$ 的扩孔样品.

图 11 降解率由高到低依次为: $\mathrm{R}_{15}>\mathrm{R}_{5}>\mathrm{R}_{20}>\mathrm{R}_{1}>$ $\mathrm{R}_{10}$. 根据 BET/BJH 分析可知, 载体的孔径由大到小依 次为: $\mathrm{R}_{15}>\mathrm{R}_{10}>\mathrm{R}_{1}>\mathrm{R}_{20}>\mathrm{R}_{5}$; 孔体积由大到小依次为: $\mathrm{R}_{1}>\mathrm{R}_{20}>\mathrm{R}_{5}>\mathrm{R}_{15}>\mathrm{R}_{10}$. 其中, $\mathrm{R}_{15}$ 的降解率为 $28.95 \%$, 是 5 个载体中最高的. 这是由于 $\mathrm{R}_{15}$ 的孔径最大, 固定酶 的比活最高, 且漆酶的分子直径和蠕虫状孔孔径相匹配, 故使得进入到孔道内的 2,4-DCP 分子的活性位点很容易 与漆酶的活性位点结合, 从而起到较好的降解效果.

比较 $\mathrm{R}_{1}$ 和 $\mathrm{R}_{10}$ 的孔体积对降解率的影响可以发现, 孔体积太大或太小都不利于降解率的提高, 这是因为孔
体积太小容易引起孔道阻塞，孔体积太大导致酶分子在 孔道内发生堆积, 活性位点不能完全暴露出来无法跟 2,4-DCP 结合使降解率下降. 此外, $\mathrm{R}_{5}$ 和 $\mathrm{R}_{20}$ 尽管孔径只 有 $3.20 \mathrm{~nm}$ 左右，与漆酶分子不相匹配，但 $\mathrm{R}_{5}$ 和 $\mathrm{R}_{20}$ 外 部表面积最大, 达到 $918.4 \mathrm{~m}^{2} / \mathrm{g}$ 左右, 漆酶分子可以固 定于介孔 $\mathrm{SiO}_{2}$ 外表面, 因而 $\mathrm{R}_{5}$ 和 $\mathrm{R}_{20}$ 固定化酶对 2,4-DCP 的降解率也比较高(见图 11).

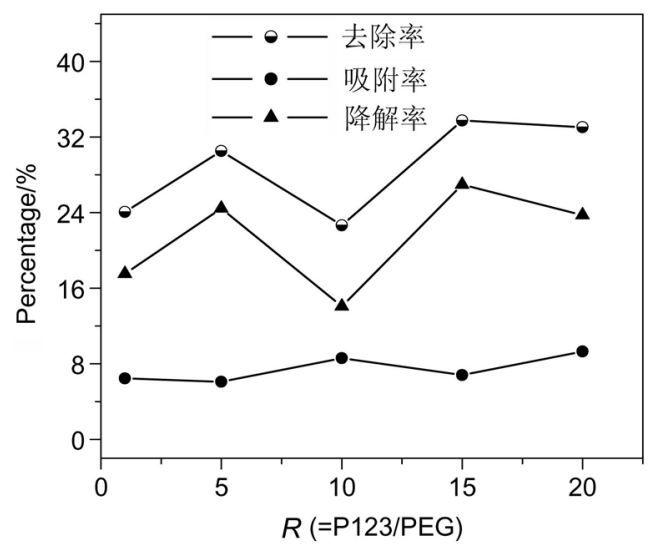

图 11 不同 PEG 添加量对固定酶降解 2,4-DCP 的影响

Figure 11 Effect of different volumes of PEG on the 2,4-DCP removal by immobilized laccase

总之, 载体的孔径、孔体积以及表面积是影响固定 酶降解率的决定性因素, 在选择载体时需综合考虑三者 的影响.

\section{5 固定化酶降解 2,4-DCP}

\subsection{1 固定化酶的最佳工作 $\mathrm{pH}$ 值}

从图 12 可以看出, 自由漆酶的最佳工作 $\mathrm{pH}$ 值为 5.0, 固定酶的最佳工作 $\mathrm{pH}$ 值为 6.0 , 固定酶的最佳工作 $\mathrm{pH}$ 值向碱性方向移动. 这是由于介孔 $\mathrm{SiO}_{2}$ 表面具有季 铵盐官能团, 使得固定化酶周围的微环境呈弱酸性, 因 而要求溶液必须具有较自由漆酶最适 $\mathrm{pH}$ 值才能达到 固定化酶的最适作用 $\mathrm{pH}$ 值. 同时固定化后酶的空间结 构受到载体的影响, 更降低了固定化酶对 $\mathrm{pH}$ 值变化的 敏感性, 比如, $\mathrm{pH}$ 从 4 增加至 5 时, 自由酶比活变化幅 度较大, 从 $277.6 \mathrm{U} / \mathrm{g}$ 增加至 $470.4 \mathrm{U} / \mathrm{g}$; 而固定化酶仅 从 $426.6 \mathrm{U} / \mathrm{g}$ 下降至 $405.7 \mathrm{U} / \mathrm{g}$. 当 $\mathrm{pH}$ 从 5 增加至 6 时, 自由酶比活从 $470.4 \mathrm{U} / \mathrm{g}$ 下降至 $244.1 \mathrm{U} / \mathrm{g}$; 而固定化酶 从 $405.7 \mathrm{U} / \mathrm{g}$ 增加至 $476.1 \mathrm{U} / \mathrm{g}$.

\subsection{2 固定化酶的操作稳定性}

从图 13 可知, 自由酶第一天的比活为 $470 \mathrm{U} / \mathrm{g}$, 第 二天迅速降为 $257 \mathrm{U} / \mathrm{g}$, 至第四天时, 比活降低为 204.6 $\mathrm{U} / \mathrm{g}$, 至第七天时, 自由酶比活仅为 $157 \mathrm{U} / \mathrm{g}$. 而固定化 酶第一天的比活为 $467.5 \mathrm{U} / \mathrm{g}$, 随着放置时间延长, 比活 降低; 至第四天时, 比活降低为 $306.5 \mathrm{U} / \mathrm{g}$. 随后固定化 酶的比活降低的比较缓慢, 到第五、第六天和第七天时, 比活仍为 $291.3 \mathrm{U} / \mathrm{g}$, 固定化酶的比活依然较高, 说明固 定化酶的操作稳定性比自由酶好. 


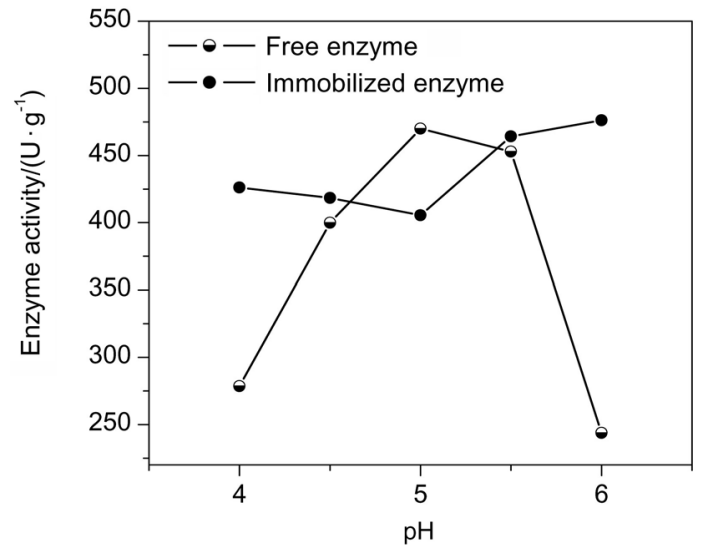

图 12 自由酶和固定酶的最佳工作 $\mathrm{pH}$ 值

Figure 12 The optimal $\mathrm{pH}$ value of free laccase and immobilized laccase

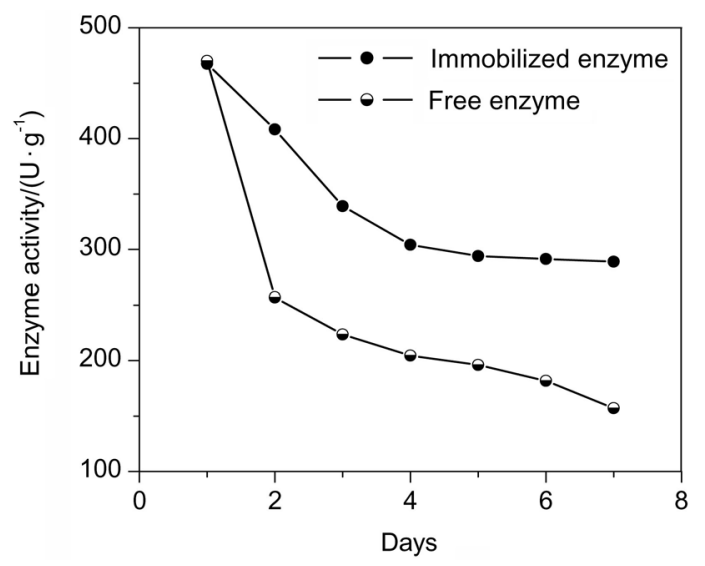

图 13 自由酶和固定化酶的操作稳定性

Figure 13 Immobilized enzyme operation stability

\subsection{3 季铵盐二氧化硅、交联载体和固定化酶红外光谱}

在载体介孔 $\mathrm{SiO}_{2}$ 的红外光谱图中, $3407 \mathrm{~cm}^{-1}$ 处出 现了强而宽的峰, 是氨基和羟基的伸缩振动峰, 2985 和 $1738 \mathrm{~cm}^{-1}$ 处出现的弱峰为季铵基官能团上 $-\mathrm{CH}_{2}$ 伸缩振 动峰, 而 $1644 \mathrm{~cm}^{-1}$ 处出现的吸收峰为季铵基中 $\mathrm{N}-\mathrm{CH}_{3}$ 的弯曲振动峰, $1494 \mathrm{~cm}^{-1}$ 处出现的吸收峰为季 铵基中甲基的 $\mathrm{C}-\mathrm{H}$ 键弯曲振动峰; 位于 1091 和 959.4 $\mathrm{cm}^{-1}$ 处的峰为 $\mathrm{SiO}_{2}$ 特征峰, 800.3 和 $462.5 \mathrm{~cm}^{-1}$ 处的峰 为 $\mathrm{Si}-\mathrm{O}-\mathrm{Si}$ 键的对称伸缩振动和弯曲振动 ${ }^{[17]}$.

戊二醛交联载体的红外光谱图中, 分别在 1719 和 $1560 \mathrm{~cm}^{-1}$ 处出现两个新峰, 前者属于戊二醛中一个游 离的醛基, 而后者为龙二醛中另一个醛基与季铵基通过 $\mathrm{p}, \pi$-超共轭作用形成的络合键. 证明戊二醛通过形成的 络合键已经牢固的结合于介孔 $\mathrm{SiO}_{2}$ 载体上.

固定漆酶后载体的红外光谱图中, 位于 $1494 \mathrm{~cm}^{-1}$ 处季铵基中甲基的 $\mathrm{C}-\mathrm{H}$ 键弯曲振动峰仍然保持不变, 而在 $1653 \mathrm{~cm}^{-1}$ 处出现较强的新吸收峰, 属于 Schiff 碱 的特征吸收峰. 这是由于戊二醛交联载体上游离的醛基 与漆酶上的氨基发生反应后, 生成 Schiff 碱, 将漆酶分
子通过共价键固定到载体的表面上.

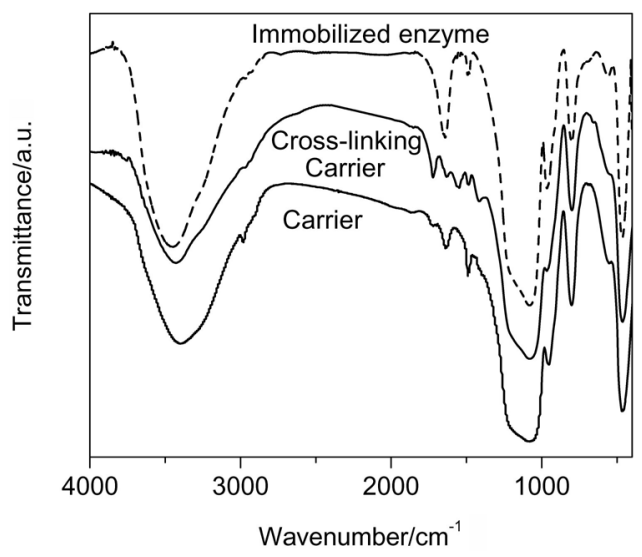

图 14 季铵盐二氧化硅、交联载体和固定化酶红外光谱

Figure 14 Infrared spectra of quaternary ammonium salt silica, crosslinking carrier and immobilized enzyme

\subsection{4 固定化酶的重复利用性}

图 15 为 $\mathrm{R}_{15}$ 固定化漆酶降解 2,4-DCP 与重复使用次 数的关系图. 从图 15 可知, 第一次固定化酶对 2,4-DCP 的降解率达到 $60.90 \%$ ，虽然第二次降解率下降到 $46.27 \%$ ，但是接下来六次重复后，降解率仍在 $42 \%$ 以上， 说明不但固定化酶的降解率较高, 而且重复利用性质也 比较稳定. Nelson 等 ${ }^{[18]}$ 在用固定化酶降解废水中的酚类 物质时，吸附在载体表面的有色产物阻止载体和酶分子 与 2,4-DCP 分子的进一步接触, 造成反复使用过程中降 解率和吸附率下降. 对此可以采用高离子浓度的缓冲溶 液反复洗涤固定酶, 减小对酶活力的影响. 催化降解产 生的不溶物是非酶反应形成的，重复使用固定酶时，沉 淀物的积累导致流速变慢甚至发生堵塞，阻碍 2,4-DCP 的催化降解. 另外, 由于在重复使用的过程中可能由于 分离及洗涤时造成有一小部分酶流失, 及在振荡过程中 造成一部分酶的活性损失, 也会造成固定酶对 2,4-DCP 的降解率变低.

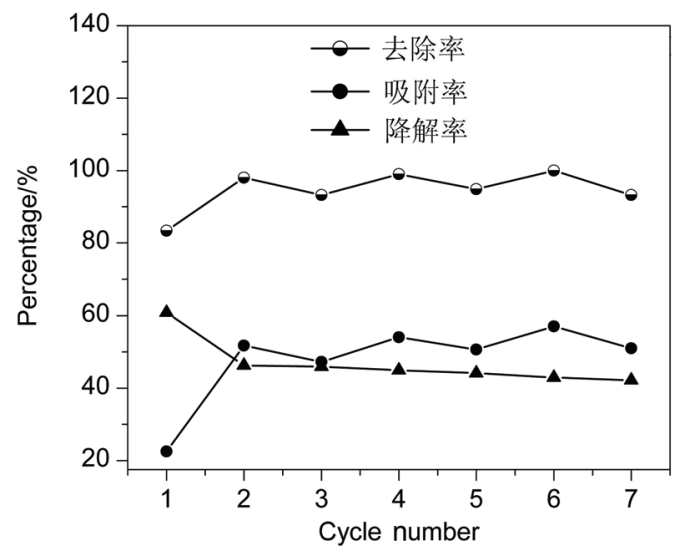

图 15 固定化漆酶连续重复使用去除 2,4-DCP

Figure 15 Continuous use immobilized laccase to elimination 2,4-DCP 


\section{6 固定化酶的稳定性, 重复利用性与孔径的关系}

在本课题组发表的论文中 ${ }^{[19]}$, 我们以十六烷基三 甲基溴化铵 (CTAB) 为模板, 合成了二维六方结构的介 孔 $\mathrm{SiO}_{2}$, 其表面积为 $1259.48 \mathrm{~m}^{2} \cdot \mathrm{g}^{-1}$, 平均孔径为 2.64 $\mathrm{nm}$, 孔体积为 $0.68 \mathrm{~cm}^{3} \cdot \mathrm{g}^{-1}$. 经过氨基化改性后成为 $\mathrm{NH}_{2}-\mathrm{SP}-3$ 样品, 其表面积降低为 $566.36 \mathrm{~m}^{2} \cdot \mathrm{g}^{-1}$, 平均孔 径为 $2.30 \mathrm{~nm}$, 孔体积为 $0.39 \mathrm{~cm}^{3} \cdot \mathrm{g}^{-1}$. 由于漆酶的分子 直径大约在 $4 \mathrm{~nm}^{[14,15]}$, 与 $\mathrm{NH}_{2}-\mathrm{SP}-3$ 样品的孔径不相匹 配, 故漆酶分子大部分只能固定于 $\mathrm{NH}_{2}-\mathrm{SP}-3$ 样品外表 面. 由于 $\mathrm{NH}_{2}-\mathrm{SP}-3$ 样品的表面积和孔体积均小于本文 中 $\mathrm{P} 123 / \mathrm{PEG}=1 / 15$ 的样品 $\left(\mathrm{R}_{15}\right)$, 因而 $\mathrm{NH}_{2}-\mathrm{SP}-3$ 样品对 漆酶的固定率较低, 对 2,4-DCP 的降解率也较低. 当第 一次使用时, $\mathrm{NH}_{2}$-SP-3 固定化漆酶对 2,4-DCP 的降解率 仅有 $15.93 \%$, 而 $\mathrm{R}_{15}$ 固定化漆酶对 2,4-DCP 的降解率却 高达 $60.90 \%$; 重复使用 4 次后, $\mathrm{NH}_{2}$-SP-3 固定化漆酶对 $2,4-\mathrm{DCP}$ 的降解率急剧降低为 $2.57 \%$, 而 $\mathrm{R}_{15}$ 固定化漆酶 对 2,4-DCP 的降解率依然高达 $44.92 \%$; 重复使用 6 次后, 降解率仍然保持在 $42 \%$ 以上. 这些充分说明, 与漆酶分 子尺寸相匹配的蠕虫状孔道结构的介孔 $\mathrm{SiO}_{2}$ 具有较大 的孔径, 孔体积和表面积, 因而其固定化酶具有较高的 重复使用性能.

\section{3 结论}

(1) 在 P123 的合成体系中加入不同类型的表面活 性剂作为助结构导向剂 (CTAB, SDS 以及 $\mathrm{C}_{14}$-D-A/TMAPS), 导致了混合超分子聚集体的形成, 是形成蠕虫状孔道介孔 $\mathrm{SiO}_{2}$ 的主要原因. 由于助结构 导向剂与 P123 及硅源三者之间的相互作用存在差异, 导致产物的孔结构参数发生改变. 当在 P123/C $14-\mathrm{D}-\mathrm{A} /$ TMAPS 的合成体系中加入不同比例的添加剂 PEG 后发 现, PEG 的加入量对于产物的孔结构参数具有一定的调 节作用. 通过控制 PEG 的加入量可以得到具有一定孔 结构参数的介孔 $\mathrm{SiO}_{2}$. 采用萃取法可以将其介孔中的表 面活性剂除去, 得到添加不同比例的 PEG 后含有季铵 盐官能团的具有三维蠕虫状孔道的介孔 $\mathrm{SiO}_{2}$ 载体.

(2) 固定化酶在 $\mathrm{pH}=6.0$ 时比活最高, 放置 7 天后 仍具有较高的比活; 具有较好的操作稳定性.

(3) 利用三维蠕虫状孔道固定化漆酶降解 2,4-DCP 后发现, 当体系中 PEG/P123 = $15 / 1$ 时, 介孔孔径与漆酶 的分子直径相匹配, 对漆酶的固定率最高, 导致对 2,4-DCP 的降解率最高, 具有较高的重复使用性能.

\section{4 实验部分}

\section{1 实验原理}

\subsection{1萃取法制备季铵盐官能团化介孔 $\mathrm{SiO}_{2}$}

以表面活性剂为结构导向剂, 通过溶胶一凝胶法制 备的介孔 $\mathrm{SiO}_{2}$ 采用萃取法将表面活性剂去除而不影响
已经形成的介孔结构 ${ }^{[20,21]}$. 当萃取体系中使用酸或盐做 萃取剂时, 介孔 $\mathrm{SiO}_{2}$ 体系中带有正电荷的四价氨基基 团通过离子交换跟酸或盐中带有负电荷的离子结合，阴 离子表面活性剂从介孔结构中释放, 从而得到位于孔道 内的具有氨基官能团化的介孔 $\mathrm{SiO}_{2}$. 如图 16 所示, 当使 用 TMAPS 做助结构导向剂时, 通过萃取可以得到季铵 盐型的介孔 $\mathrm{SiO}_{2}$ 载体.

\subsection{2 季铵盐官能团化介孔 $\mathrm{SiO}_{2}$ 固定化漆酶}

第一步: 由于戊二醛中的 $\mathrm{CHO}$ 双键含有一个 $\pi$ 键, 氮由于形成季铵盐而存在一个空的 $\mathrm{p}$ 轨道, 二者通过 $\mathrm{p}$, $\pi$-超共轭作用生成络合物 ${ }^{[22,23]}$. 从而成功的将戊二醛交 联在硅基载体上.

第二步：跟戊二醛交联的硅基载体通过另外一个 $\mathrm{CHO}$ 与漆酶分子上的 $-\mathrm{NH}_{2}$ 发生反应形成 Schiff 碱, 从 而使漆酶牢固地结合在交联介孔二氧化硅颗粒上. 发生 的主要反应如下:

$$
\begin{aligned}
& \mathrm{SiO}_{2}-\mathrm{N}^{+}\left(\mathrm{CH}_{3}\right)_{3} \mathrm{Cl}^{-}+\mathrm{OHC}-\left(\mathrm{CH}_{2}\right)_{3} \mathrm{CHO} \rightarrow \text { 硅基季铵 } \\
& \text { 盐/戊二醛络合物(-CHO) }
\end{aligned}
$$

硅基季铵盐/戊二醛络合物 $-\mathrm{CHO}+\mathrm{NH}_{2}$-Laccase $\rightarrow$ 硅基载体-Laccase

\section{2 实验方法}

\subsubsection{N-肉豆冦酰- $D$-丙氨酸 $\left(\mathrm{C}_{14}-\mathrm{D}-\mathrm{A}\right)$ 的制备}

将 $5.85 \mathrm{~g} \mathrm{D}$-丙氨酸溶解于盛有 $25 \mathrm{~mL}$ 水、 $25 \mathrm{~mL}$ 丙 酮和 $4 \mathrm{~g}$ 氢氧化钠的三颈烧瓶中, 调节 $\mathrm{pH}$ 值为 $8 \sim 10$. 然后, 在 $0 \sim 5{ }^{\circ} \mathrm{C}$, 搅拌下同时滴加 $16.5 \mathrm{~g}$ 浓度为 $24 \%$ 的氢氧化钠溶液和 $13.5 \mathrm{~g}$ 肉豆莘酰氯, 反应时间 $1.5 \mathrm{~h}$. 反应结束后, 用浓盐酸酸化反应物至 $\mathrm{pH}$ 值为 1 , 得白色 的 $N$-肉豆冦酰- $D$-丙氨酸絮状沉淀. 静置后, 用石油醚 洗涤数次, 得到白色的固体样品, 并在乙醇/水(体积比 为 $3: 7$ )混合溶剂中重结晶, 干燥. $N$-肉豆冦酰- $D$-丙氨 酸的核磁分析: ${ }^{1} \mathrm{H}$ NMR (600 MHz, $\left.\mathrm{D}_{2} \mathrm{O}, \mathrm{TMS}\right) \delta: 0.71[\mathrm{t}$, $\left.3 \mathrm{H}, \mathrm{CH}_{3}-\left(\mathrm{CH}_{2}\right)_{12^{-}}\right], 1.12 \sim 1.25\left[\mathrm{~m}, 20 \mathrm{H}, \mathrm{CH}_{3}-\left(\mathrm{CH}_{2}\right)_{10^{-}}\right]$, 1.31 (d, 3H, CH $3-\mathrm{CH}-), 2.68$ (tt, $\left.2 \mathrm{H},-\mathrm{CH}_{2}-\mathrm{CH}_{2}-\mathrm{CO}-\right), 3.05$ (t, 2H, - $\mathrm{CH}_{2}-\mathrm{CO}-$ ), 3.60 (dq, $1 \mathrm{H},-\mathrm{NH}-\mathrm{CH}-\mathrm{CH}_{3}$ ).

\subsection{2 蠕虫状孔道的介孔 $\mathrm{SiO}_{2}$ 的合成}

在典型合成反应体系中, $35{ }^{\circ} \mathrm{C}$ 下, 将 $1.16 \mathrm{~g}$ P123与 $0.015 \mathrm{~g} \mathrm{C}_{14}$-D-A 混合溶于去 $25 \mathrm{~mL}$ 离子水中, 待溶液搅 拌至澄清后加入 $12.5 \mathrm{~mL} \mathrm{HNO}_{3}$ 溶液, 向体系中滴加 $2.79 \mathrm{~mL}$ TEOS, 搅拌晶化 $24 \mathrm{~h}$ 后, 于 $100{ }^{\circ} \mathrm{C}$ 老化 $24 \mathrm{~h}$. 将所得白色粉末抽滤水洗, 室温下晾干, 于 $500{ }^{\circ} \mathrm{C}$ 下煅 烧 $6 \mathrm{~h}$.

由于 $\mathrm{EtOH}$ 加入量和助结构导向剂 TMAPS 均会影 响介孔 $\mathrm{SiO}_{2}$ 的结构, 我们在典型合成反应体系中, 向体 系中加入 $0.9 \mathrm{~mL} \mathrm{EtOH}$, 形成 $\mathrm{P} 123 / \mathrm{C}_{14}-\mathrm{D}-\mathrm{A} / \mathrm{EtOH}$ 合成 反应体系; 在此基础上, 再滴加 $0.42 \mathrm{~mL}$ TMAPS, 便形 成典型的 $\mathrm{P} 123 / \mathrm{C}_{14}-\mathrm{D}-\mathrm{A} / \mathrm{TMAPS}$ 合成反应体系. 


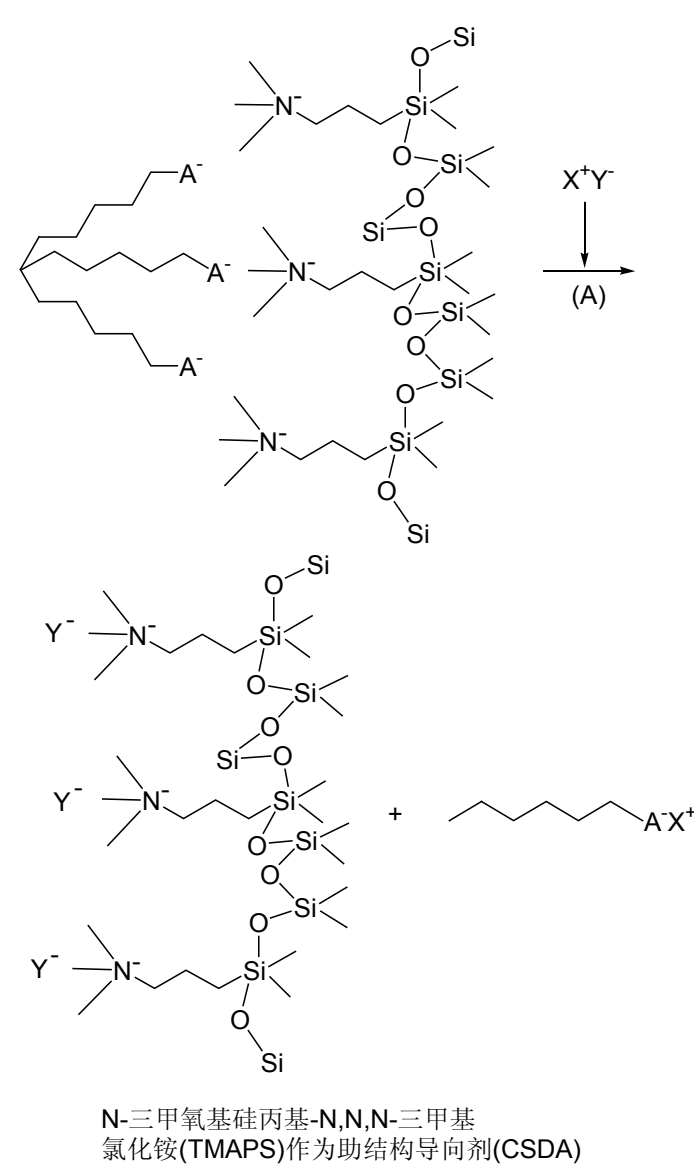

图 16 萃取法制备季铵盐官能团化介孔 $\mathrm{SiO}_{2}$ 示意图

Figure 16 Scheme of quaternary ammonium group functionalized mesoporous silica formed by extraction

(1) 为了研究扩孔剂 PEG-400 对介孔 $\mathrm{SiO}_{2}$ 孔径, 孔 体积等参数的影响, 在典型的 P123/C $14-\mathrm{D}-\mathrm{A} / \mathrm{TMAPS}$ 合 成反应体系中, 分别加入不同体积的 PEG 溶液 $(0.1 \mathrm{~mL}$, $0.5 \mathrm{~mL}, 1 \mathrm{~mL}, 1.5 \mathrm{~mL}, 2.0 \mathrm{~mL}$ ), 而其它反应条件保持不 变.

(2) 为了研究不同离子型表面活性剂(ISA)对介孔 $\mathrm{SiO}_{2}$ 结构的影响, 在典型的 $\mathrm{P} 123 / \mathrm{C}_{14}-\mathrm{D}-\mathrm{A} / \mathrm{EtOH}$ 合成反 应体系中, 将 $0.015 \mathrm{~g} \mathrm{C}_{14}$-D-A 分别改为 $0.018 \mathrm{~g} \mathrm{CTAB}$ 和 $0.014 \mathrm{~g} \mathrm{SDS}$, 而其它反应条件保持不变. 三种反应的 物质的量比均可以表示为：0.016P123：0.004ISA： $6 \mathrm{HNO}_{3}:$ TEOS : $166 \mathrm{H}_{2} \mathrm{O}$, 其中 ISA 分别指 $\mathrm{C}_{14}$-D-A, CTAB 和 SDS.

\subsubsection{2,4-DCP 的测定}

2,4-DCP 浓度采用 4-氨基安替比林比色法测定. 即 取待测 2,4-DCP 溶液 $10 \mathrm{~mL}$, 用去离子水稀释至 $100 \mathrm{~mL}$, 加入 $2.5 \mathrm{~mL} 0.5 \mathrm{~mol} / \mathrm{L} \mathrm{NH}{ }_{3} \cdot \mathrm{H}_{2} \mathrm{O}$ 溶液, 用磷酸盐缓冲溶 液调节 $\mathrm{pH}$ 值为 7.9, 依次加入 $1.0 \mathrm{~mL} 2 \%$ 4-氨基安替比 林溶液、 $1.0 \mathrm{~mL} 80 \mathrm{~g} / \mathrm{L} \mathrm{K}_{3}\left[\mathrm{Fe}(\mathrm{CN})_{6}\right]$ 溶液, 混匀. 在室温 下反应一段时间后, 以去离子水和试剂的混合溶液为空 白, 根据在 $510 \mathrm{~nm}$ 处所测吸光度与酚类化合物的浓度 成正比, 得出所测吸光度对 2,4-DCP 浓度的标准曲线,
进一步根据在 $510 \mathrm{~nm}$ 处所测吸光度, 得出 2,4-DCP 的实 际浓度 ${ }^{[4]}$.

\subsection{4 介孔 $\mathrm{SiO}_{2}$ 载体固定化酶}

(1) 介孔 $\mathrm{SiO}_{2}$ 载体的制备

介孔 $\mathrm{SiO}_{2}$ 载体的制备按照 4.2.2 节中典型的 P123/C 14 -D-A/TMAPS 合成反应体系进行. 所不同的是, 样品室温晾干后, 采用萃取法除去表面活性剂. 具体方 法为: 分别称取 $1 \mathrm{~g}$ 干燥后的产物分散于无水乙醇/盐酸 的混合溶液中(体积为 $89: 11$ ), $100{ }^{\circ} \mathrm{C}$ 下回流 $24 \mathrm{~h}$. 将 所得白色粉末抽滤, 醇洗, $60{ }^{\circ} \mathrm{C}$ 下真空干燥 $2 \mathrm{~h}$. 所得 产物即为季铵盐介孔 $\mathrm{SiO}_{2}$ 载体.

(2) 固定酶酶活力的检测

分别取 $1 \mathrm{~mL}$ 新配制的漆酶溶液和 $0.1 \mathrm{~g}$ 固定酶于 5 $\mathrm{mL} 4 \mathrm{mmol} \cdot \mathrm{L}^{-1}$ 愈创木酚溶液中, 加入 $5 \mathrm{~mL} \mathrm{pH}=5.4$ 的 醋酸-醋酸钠缓冲溶液, 在 $30{ }^{\circ} \mathrm{C}$ 下恒温反应 $30 \mathrm{~min}$, 反 应后用高速离心机分离 $1 \mathrm{~min}$, 用针筒吸取 $5 \mathrm{~mL}$ 上层清 液, 注入比色皿, 在 $465 \mathrm{~nm}$ 下测其吸光度. 参比溶液为 $1 \mathrm{~mL}$ 煮沸酶液依次加入上述物质, 在相同条件下反应 $30 \mathrm{~min}$. 固定化酶的总活力可以按式(3)计算出来.

酶活力 $=1000 X / t$

$X$ 为溶液吸光度, $t$ 为酶促反应时间, 单位为分钟.

固定化酶比活力 $=$ 固定化酶的总活力/固定化酶的

$$
\text { 干质量 }
$$

(3) 漆酶的固定化及固定化酶的操作最佳 $\mathrm{pH}$ 值

在 $25{ }^{\circ} \mathrm{C}$ 下, 取 $0.1 \mathrm{~g}$ 季铵盐介孔 $\mathrm{SiO}_{2}$ 载体与 $10 \mathrm{~mL}$ 戊二醛(4\%)在 $25{ }^{\circ} \mathrm{C}$ 下振荡反应后, 离心分离, 并用去 离子水洗去未反应的戊二醛, 此载体称为交联载体.

将交联载体加入 $10 \mathrm{~mL}$ 漆酶溶液 $\left(0.2 \mathrm{~g} \cdot \mathrm{L}^{-1}\right)$ 和 10 $\mathrm{mL} \mathrm{pH}=5.4$ 的醋酸-醋酸钠缓冲溶液中, 振荡反应 $6 \mathrm{~h}$ 后, 离心分离, 洗涤, 即得固定化漆酶, 低温冷藏备用.

然后，分别配制浓度为 $0.2 \mathrm{~mol} / \mathrm{L}, \mathrm{pH}=4,4.5,5,5.5$, 6 的缓冲溶液, 按照 4.2.4 节(2)中的方法, 将固定化酶加 入愈创木酚和 $\mathrm{pH}=4,4.5,5,5.5,6$ 的的缓冲溶液中, 恒 温反应 $30 \mathrm{~min}$ 后, 离心分离, 取上层清液在 $465 \mathrm{~nm}$ 下 测其吸光度, 并按式(3)计算比活.

(4)自由酶和固定化漆酶的操作稳定性

将自由酶溶液和湿态固定酶分别在 $4{ }^{\circ} \mathrm{C}$ 下保存 1,2 , $3,4,5,6$ 和 7 天后, 每天分别取 $1 \mathrm{~mL}$ 漆酶溶液和 $0.1 \mathrm{~g}$ 固定酶按照 4.2.4 节(2)中的方法, 测定自由酶和固定化 漆酶的比活.

\subsection{5 固定化酶降解 2,4-DCP 农药}

(1) 固定化漆酶降解 2,4-DCP

在 $25{ }^{\circ} \mathrm{C}$ 下, 分别取 $0.2 \mathrm{~g}$ 固定化酶于 $10 \mathrm{~mL}$ 浓度为 $30 \mathrm{mg} / \mathrm{L}$ 的 2,4-DCP 溶液中, 加入 $10 \mathrm{~mL} \mathrm{pH}=5.4$ 的醋酸 醋酸钠缓冲溶液, 在 $30{ }^{\circ} \mathrm{C}$ 下应 $6 \mathrm{~h}$ 后, 过滤, 收集滤 液. 另取 $0.2 \mathrm{~g}$ 交联载体在相同条件下做吸附实验, 吸附 平衡后，收集滤液. 取 $10 \mathrm{~mL}$ 上清液，根据 4.2.3 节测定 
出 2,4-DCP 被降解后的浓度.

(2)固定化酶降解 2,4-DCP 农药的使用寿命

取 $0.2 \mathrm{~g}$ 固定化漆酶于 $10 \mathrm{~mL}$ 的 $10 \mathrm{mg} \cdot \mathrm{L}^{-1}$ 的 2,4-DCP 溶液中, 加入 $10 \mathrm{~mL} \mathrm{pH}=5.0$ 的醋酸-醋酸钠缓 冲溶液, 在 $30{ }^{\circ} \mathrm{C}$ 下反应 $6 \mathrm{~h}$ 后, 过滤, 取 $10 \mathrm{~mL}$ 2,4-DCP 滤液, 按 4.2.3 节方法测定降解后的 2,4-DCP 浓 度. 利用交联载体在相同条件下做吸附实验, 同样测定 出吸附后 2,4-DCP 的浓度.

每次实验过后, 将分离得到的固定酶及空白载体用 去离子水洗涤干净, 放在冰箱中冷藏, 第二天重复上述 实验, 连续重复 6 次, 用测得吸光度计算出 2,4-DCP 的 去除率、吸附率及降解率.

(3) 2,4-DCP 去除率、降解率和吸附率的计算方法参 考本课题组发表的论文 ${ }^{[19]}$.

\section{References}

[1] Kim, S.; Pauly, T.; Pinnavaia, T. Chem. Commun. 2000, 835

[2] Park, I.; Pinnavaia, T. J. Microporous Mesoporous Mater. 2009, 118,239

[3] Yang, Y. X.; Zhang, J. B.; Liu, X. N.; Chen, Y. R.; Jia, X. C. J. Am. Cera. Soc. 2007, 90, 2050.

[4] Yang, Y. X.; Xiang, W. D.; Zheng, J. L.; Yuan, H. M.; Ying, H. P. Adv. Sci. Lett. 2011, 4, 561

[5] Kim, T. W.; Kleitz, F.; Paul, B.; Ryoo, R. J. Am. Chem. Soc. 2005, $127,7601$.

[6] Jin, Z.-W.; Wang, X.-D. Acta Chim. Sinica 2008, 66, 1519. (金政 伟, 汪晓东, 化学学报, 2008, 66, 1519.)

[7] Sel, O.; Kuang, D. B.; Thommes, M.; Smarsly, B. Langmuir 2006, $22,2311$.
[8] Li, F.; Wang, Z. Y.; Ergang, N. S.; Fyfe, C. A.; Stein, A. Langmuir 2007, 23, 3996

[9] Xu, R.-R.; Pang, W.-Q.; Yu, J.-H.; Huo, Q.-S.; Chen, J.-S. Molecular Sieve and Porous Materials Chemistry, Science Press, Beijing, 2005, p. 558. (徐如人，庞文琴，于吉红，霍启升，陈接胜, 分子篮与多孔材料化学, 科学出版社, 北京, 2005, p. 588.)

[10] Guo, J. M.S. Thesis, Nanjing University of Aeronautics and Astronautics, Nanjing, 2007. (郭静, 硕士论文, 南京航空航天大学, 南 京, 2007.)

[11] Wan, Y.; Zhao, D.-Y. Chem. Rev. 2007, 107(7), 2821

[12] Tanev, P. T.; Pinnavaia, T. J. Science 1995, 267, 865.

[13] Yu, C.-Z.; Fan, J.; Tian, B.-Z.; Zhao, D.-Y. Chem. Mater. 2004, 16, 889.

[14] Alm, M. Y.; Martinez, C. E.; Archibald, D. D.; Zimmerman, A. R.; Bollag, J. M.; Dec, J. Soil Biol. Biochem. 2006, 38, 1015.

[15] Zimmerman, A. R.; Goyne, K. W.; Komarneni, S.; Chorover, J.; Kubicki, J.; Brantley, S. L. Org. Geochem. 2004, 35, 355.

[16] Li, Y.-J.; Zhou, G.-W.; Xing, F.-Q. Appl. Chem. Ind. 2008, 37, 688. (李艳敬, 周国伟, 邢凡勤, 应用化工, 2008, 37, 688.)

[17] Wang, Z.-Y.; Zhang, L.-P.; Yang, Y.-X. Glass Phys. Chem. 2009, 35,673 .

[18] Nelson, D.; Maria, A. R.; Alessandro, D. A.; Liliana, G. Enzyme Microb. Technol. 2002, 31, 926.

[19] Yang, Y.-X.; Zhang, Y.-N.; Shao, J.-G.; Chen, Y.-R. J. Tongji Univ. (Nat. Sci. Ed.) 2011, 39, 1324, 1393. (杨宇翔, 张亚妮, 邵建国，陈娅如，同济大学学报(自然科学版)，2011，39，1324, 1393.)

[20] Zhao, D.-Y.; Huo, Q.-S.; Feng, J.-L.; Chmelka, B. F.; Stucky, G. D. J. Am. Chem. Soc. 1998, 120, 6024.

[21] Zheng, H.-Q.; Gao, C.-B.; Che, S.-N. Microporous Mesoporous Mater. 2008, 116, 299.

[22] Zhang, X.-L.; Kang, H. Coordination Chemistry, Central South University of Technology Press, Changsha, China, 1986, pp. 707 716. (张祥麟, 康衡, 配位化学, 中南工业大学出版社, 长沙, 1986, pp. 707 716.)

[23] Gao, H.-B. Organic Chemistry, Higher Education Press, Beijing, 2004, pp. 98 100. (高鸿宾, 有机化学, 高等教育出版社, 北京, 2004, pp. $98 \sim 100$.) 